\title{
Studi Deskriptif Program Suplementasi Tablet Besi Pada Ibu Hamil Di Puskesmas Kalijudan Kota Surabaya
}

\section{Descriptive Study of Iron Tablet Supplementation Program on Pregnant Women in Kalijudan Public Health Center Surabaya City}

\author{
Nadia Kenyo Peni Dewantoro*1, Lailatul Muniroh ${ }^{1}$
}

\begin{abstract}
ABSTRAK
Latar belakang: Suplementai Tablet Besi merupakan salah satu program pemerintah dalam upaya menurunkan prevalensi anemia pada ibu hamil. Nilai rata-rata cakupan pemberian tablet besi pada ibu hamil di wilayah kerja Dinas-Kesehatan-Kota Surabaya selama tiga tahun terakhir mengalami penurunan. Bila nilai cakupan ditinjau pada tiap puskesmas, maka terdapat beberapa puskesmas yang cakupannya mengalami peningkatan salah satunya yakni Puskesmas Kalijudan tetapi belum diikuti dengan penurunan prevalensi anemia ibu hamil.

Tujuan: Penelitian ini bertujuan untuk mengetahui pelaksanaan program suplementasi tablet besi di Puskesmas Kalijudan dengan menggunakan pendekatan sistem.

Metode: Jenis penelitian ini ialah kualitatif yang melibatkan 8 orang tenaga kesehatan dan 15 orang ibu hamil sebagai informan. Penentuan keterlibatan informan menggunakan teknik purposive sampling dan accidental sampling.

Hasil: Tahap input, tenaga kesehatan dalam program berasal dari berbagai profesi dan sudah cukup dari segi jumlah dan kualifikasi. Dana pembelian tablet berasal dari Jaminan Kesehatan Nasional. Alat periksa hemoglobin adalah hematology analyzer dan dioperasikan oleh petugas laboratorium. Ketersediaan tablet besi mengalami kekurangan. Segi tahap proses, perencanaan tablet besi dilakukan satu tahun sekali dan pengadaan mengikuti jadwal Dinas-Kesehatan-Kota-Surabaya. Banyaknya tablet yang diberi pada ibu hamil dalam satu kali kunjungan mengikuti jadwal kontrol atau 15 tablet. Monitoring kepatuhan konsumsi tablet dilakukan dengan wawancara sederhana. Pengorganisasian tenaga kesehatan khusus pelaksana program tablet besi belum ada. Segi tahap output, pencatatan persentase cakupan hanya dilakukan setiap akhir tahun. Segi tahap outcome, prevalensi anemia ibu hamil tidak dapat diketahui.

Kesimpulan: Pelaksanaan program suplementasi tablet besi dapat dikatakan belum berjalan dengan baik, dikarenakan masih terdapat kendala di beberapa tahapan.
\end{abstract}

Kata kunci: program suplementasi, tablet besi, anemia, ibu hamil, studi deskriptif kualitatif 


\section{ABSTRACT}

Background: Supplementation of iron tablet is one of the government program that aims to decrease prevalence of-anemia on pregnant-women. The average corevage of iron tablet program on pregnant women in the work area of-Distric-Health-Government of Surabaya over past three years has decrease. If coverage value is reviewed by each public-health-center, there are some publichealth-center whose coverage is increased one of-them is Kalijudan Public-Health-Center but is not followed by a-decrease number of anemia in pregnant women.

Objectives: This research aims was to describe the implementation of-iron tablet program in Kalijudan-Public Health-Center and used system approach.

Methods: The type of- this research was qualitative and involved 8-health workers and 15 pregnantwomen as informants. Determination of informant involvement used purposive sampling and accidental sampling technic.

Results: Health workers that involved came from various profession and were sufficient in terms quantity and qualification. The funds used for iron tablet purchases came from National-HealthInsurance. The hemoglobin examination tool was hematology analyzer and operated by laboratory worker. The availability of-iron tablets was deficience. The process stage, iron tablets planning was done once per year and its procurement followed schedule from Distric-Health-Government. The number of tablets was given to pregnant-women in a-single visit followed a-control schedule or 15tablets. The monitoring of iron tablet consumption compliance was done with simple interview. Special organizing of-health workers for program did not yet exist. The output stage, recording coverage percentages were performed at the end of each year. The outcome stage, prevalence ofanemia in pregnant-women could not be known.

Conclusion: The implementation of-program can be said not run well, because there are still some obstacles.

Keywords: program supplementation, iron tablet, anemia, pregnant women, descriptive qualitative study

*Koresponden:

kenyonadia@gmail.com

${ }^{1}$ Departemen Gizi Kesehatan, Fakultas

Kesehatan Masyarakat-Universitas Airlangga

\section{PENDAHULUAN}

Pemenuhan gizi terhadap ibu hamil (bumil) merupakan salah satu aspek penting yang perlu diperhatikan selama masa kehamilan berlangsung. Hal tersebut seiring dengan diharapkannya outcome kehamilan yang baik, yakni generasi penerus yang sehat, pintar, serta mampu memiliki tingkat produktivitas yang tinggi ${ }^{1}$. Tetapi hingga saat ini, kelompok ibu hamil masih sering dihadapkan dengan berbagai permasalahan kesehatan yang salah satunya adalah anemia gizi besi². Masalah anemia yang dihadapi ibu hamil di negara berkembang, diketahui pula mampu memberi dampak pada anak yang dikandungnya ${ }^{3}$. Disisi lain, anemia juga mampu berkontribusi signifikan dalam meningkatkan angka kematian ibu ${ }^{3}$.

World Health Organization (WHO) tahun 2008 menyebutkan bahwa diperkirakan sebesar $41,8 \%$ dari ibu hamil yang ada di seluruh dunia mengalami anemia ${ }^{4}$. Nilai persentase prevalensi anemia pada kelompok ibu hamil di Indonesia menurut data tahun 2013 mencapai $37,1 \%{ }^{5}$. Risiko anemia pada ibu hamil didapati lebih tinggi pada ibu hamil usia remaja, kehamilan janin lebih dari satu, 
maupun jarak kehamilan yang pendek $^{6}$. Mayoritas penyebab kejadian anemia yang ada di seluruh dunia disebabkan oleh defisiensi terhadap zat besi ${ }^{7}$. Iron deficiency anemia (IDA) merupakan tipe anemia mayoritas yang ditemui pada ibu hamil dan 50-60\% disebabkan karena rendahnya asupan zat besi ${ }^{8}$.

Salah satu upaya yang dimiliki oleh Pemerintah Indonesia adalah program Suplementasi Tablet Tambah Darah (TTD) atau Tablet Besi ${ }^{9}$. Program tersebut ditujukan untuk Wanita Usia Subur, termasuk juga ibu hamil dan telah ada sejak tahun $1975^{\circ}$. Program tablet besi tersebut, dikenal dengan sebutan TTD Program karena ditujukan terutama bagi sasaran yang kurang mampu ${ }^{9}$. Pemberian suplementasi tablet besi ini, juga menjadi kegiatan yang disarankan dalam pelayanan antenatal care $(\mathrm{ANC})^{4}$. Program ini diluncurkan karena masih rendahnya kemampuan masyarakat dalam memenuhi kebutuhan zat besi yang bersumber dari makanan ${ }^{9}$.

Program suplementasi tablet besi pada bumil tersebut, salah satunya telah dilaksanakan oleh Dinas Kesehatan Kota (DKK) Surabaya. Pusat Kesehatan Masyarakat (Puskesmas) Kalijudan merupakan salah satu puskesmas yang berada di bawah wilayah kerja Dinas Kesehatan Kota Surabaya dengan angka cakupan Fe-1 dan Fe-3 mengalami tren peningkatan, namun prevalensi bumil anemia belum ikut mengalami penurunan. Cakupan Fe-1 yang diperoleh Puskesmas Kalijudan pada kurun waktu 2014-2016 ialah 92,09\%, 100,8\%, dan 98,84\%. Pada cakupan Fe-3 dalam kurun waktu 2014-2016 mencetak angka 90,45\%, 97,23\%, dan 100,14\%. Sementara itu, prevalensi bumil anemia di Puskesmas Kalijudan di tahun 2014 mencapai 16,4\% dan mengalami peningkatan menjadi $25,71 \%$ di tahun 2016. Data tersebut bila diselaraskan dengan tujuan dari program suplementasi tablet besi, masih dikatakan belum bisa mencapai tujuan. Persentase prevalensi bumil anemia di Puskesmas Kalijudan tahun 2016 tersebut, menjadi salah satu angka yang tertinggi di wilayah kerja DKK Surabaya.

Berdasarkan uraian latar belakang di atas, maka penelitian yang dilakukan bertujuan untuk mengetahui bagaimana pelaksanaan atau penyelenggaraan program suplementasi tablet besi pada bumil di tingkat puskesmas Kota Surabaya. Kegiatan tesebut dilakukan dengan menggunakan pendekatan sistem, yakni usaha dalam memecahkan suatu masalah dengan menggunakan metode ilmiah ${ }^{10}$. Melalui pendekatan sistem tersebut, evaluasi dapat dilakukan terhadap unsur atau komponen input, proses, output, dan outcome yang ada pada program suplementasi tablet besi pada bumil di Puskesmas Kalijudan.

\section{METODE}

Penelitian ini termasuk dalam jenis penelitian deskriptif, dengan tujuan menggambarkan pelaksanaan atau penyelenggaraan dari program suplementasi tablet besi pada bumil di Puskesmas Kalijudan tahun 2017. Penelitian ini berlangsung selama 1 bulan (bulan Juli-Agustus) tahun 2017. Pendekatan yang dilakukan ialah melalui pendekatan kualitatif yang bertujuan untuk membuat mengenai ramalan terhadap apa yang diteliti dari hasil penelitian yang dihimpun di lapangan ${ }^{11}$. Dalam penelitian ini digunakan pendekatan sistem (system approach) untuk menggambarkan pelaksanaan program suplementasi tablet besi. Variabel yang diteliti dalam penelitian ini meliputi 6M (man, money, machine, material, method, dan market) pada variabel input, POAC (planning, organizing, actuating, dan controlling) pada variabel proses, serta variabel output dan outcome. Teknik pengumpulan data yang digunakan yaitu wawancara mendalam (indepth interview), telaah dokumen, serta observasi.

Dalam penelitian ini, penentuan informan yang terlibat menggunakan teknik purposive sampling dan accidental sampling. Teknik purposive sampling ditujukan untuk menentukan informan yang berasal dari petugas puskesmas (tenaga kesehatan). Berdasarkan penggunaan teknik purposive sampling, maka didapatkan 8 orang petugas puskesmas yang terlibat. Petugas puskesmas tersebut terdiri dari 1 orang Kepala Puskesmas, 1 orang petugas gizi, 1 orang petugas apoteker/farmasi, 1 orang bidan koordinator, 3 bidan kelurahan, dan 1 orang petugas 
laboratorium. Sementara itu, accidental sampling ditujukan untuk menentukan jumlah informan yang berasal dari kelompok sasaran penerima program tablet besi (bumil). Jumlah ibu hamil yang bisa didapatkan hingga akhir penelitian adalah sebanyak 15 orang.

\section{HASIL DAN PEMBAHASAN}

Segi aspek input, didapatkan bahwa karakteristik kelompok sasaran penerima program (ibu hamil) menunjukkan hasil beragam dari berbagai indikator/aspek. Pada Tabel 1 dan Tabel 2 dapat terlihat distribusi ibu hamil berdasarkan usia ibu, usia kandungan, pendidikan terakhir ibu, pekerjaan/profesi ibu, serta pengetahuan ibu mengenai tablet besi dan anemia. Usia ibu hamil yang paling banyak ditemui ialah rentang usia 25-27 tahun. Sementara itu, sebagian besar ibu hamil yang ditemui memiliki usia kandungan 20-23 minggu. Mayoritas bumil yang ditemui beprofesi sebagai ibu rumah tangga (IRT) dan pendidikan terkahir ibu hamil yang paling banyak ditemui berada pada tingkat SLTA/Sederajat. Adapun ibu hamil sebanyak $66,6 \%$ menjawab dengan benar mengenai definisi anemia dan 73,33\% menjawab benar mengenai manfaat dari konsumsi tablet besi. Selain itu, sebanyak 53,33\% ibu hamil menjawab dengan benar efek samping dari konsumsi tablet besi.

Tabel 1. Distibusi Ibu Hamil Menurut Usia Ibu, Usia Kandungan, Pendidikan Terakhir, dan Pekerjaan/Profesi Ibu Hamil Tahun 2017

\begin{tabular}{lcc}
\hline \multicolumn{1}{c}{ Karakteristik Ibu Hamil } & Jumlah $(\mathbf{n})$ & Persentase (\%) \\
\hline Usia ibu hamil & 1 & 6,67 \\
$22-24$ & 8 & 53,33 \\
$25-27$ & 3 & 20 \\
$28-30$ & 1 & 6,67 \\
$31-33$ & 2 & 13,33 \\
$\geq 34$ & & \\
Usia Kandungan Ibu Hamil & 1 & 6,67 \\
$16-19$ & 5 & 33,33 \\
$20-23$ & 2 & 13,33 \\
$24-27$ & 5 & 33,33 \\
$28-31$ & 2 & 13,33 \\
$\geq 32$ & & \\
Pendidikan Terakhir Ibu Hamil & 2 & 13,33 \\
SD/Sederajat & 3 & 20 \\
SLTP/Sederajat & 6 & 40 \\
SLTA/Sederajat & 4 & 26,67 \\
Akademi/Sederajat & & \\
Pekerjaan/Profesi Ibu Hamil & 8 & 53,33 \\
Ibu Rumah Tangga (IRT) & 6 & 40,00 \\
Sektor Swasta & 1 & 6,67 \\
Perdagangan & 15 & 100 \\
\hline TOTAL & & \\
\hline
\end{tabular}

Tabel 2. Distribusi Ibu Hamil Menurut Pengetahuan Mengenai Tablet Besi dan Anemia Tahun 2017

\begin{tabular}{lcc}
\multicolumn{1}{c}{ Pertanyaan } & Jumlah Jawaban Benar (n) & Persentase (\%) \\
\hline Definisi anemia & 10 & 66,67 \\
Manfaat konsumsi tablet besi & 11 & 73,33 \\
Efek samping konsumsi tablet besi & 8 & 53,33 \\
\hline
\end{tabular}


Menurut hasil wawancara kepada informan didapatkan tenaga kesehatan (nakes) yang terlibat pada program suplementasi tablet besi berasal dari berbagai profesi, seperti 1 orang petugas gizi, 1 orang petugas farmasi, dan 6 orang bidan untuk 3 wilayah kerja puskesmas. Tenaga kesehatan yang telah disebutkan oleh informan tersebut, termasuk ke dalam tenaga kesehatan minimal yang sesuai dengan Peraturan Menteri Kesehatan Nomor 75 Tahun 2014 Tentang Puskesmas ${ }^{12}$. Terdapat pula hasil penelitian di Puskesmas Binamu Kabupaten Jeneponto yang menyebutkan kuota 6 bidan untuk 4 wilayah kerja puskesmas sudah mencukupi, namun tanpa dilengkapi dengan apa yang menjadi tolak ukurnya dan belum tentu bisa menggambarkan untuk bidan puskesmas di Kota Surabaya ${ }^{13}$.

Bila tenaga kesehatan tersebut ditinjau dari segi jumlah dan kualifikasi, maka seluruh informan menjawab telah dirasa cukup. Referensi mengenai pedoman khusus yang ditujukan untuk penentuan jumlah, kualifikasi tenaga kesehatan, serta pembagian tugas/tanggung jawab tenaga kesehatan yang terlibat dalam program suplementasi tablet besi belum ditemukan. Adapun tugas/tanggung jawab tenaga kesehatan dalam program tablet besi menurut berbagai informan ialah kolaborasi antar petugas gizi dan farmasi betugas dalam pengadaan/perencanaan tablet besi bagi puskesmas, bidan bertugas dalam pemberian tablet besi pada ibu hamil. Hal ini juga sesuai dengan hasil penelitian di Puskesmas Madakareya Kota Makassar yang menyebutkan bahwa pendistribusian tablet besi kepada bumil merupakan tugas dari bidan $^{14}$.

Sumber dana yang dipergunakan puskesmas untuk memenuhi kebutuhan tablet besi itu sendiri, berasal dari dana JKN (berdasarkan besaran kapitasi per puskesmas). Besaran dana tersebut tidaklah selalu sama antar puskesmas. Ketersediaan tablet besi di Puskesmas Kalijudan pada bulan Juli-Agustus 2017, ternyata mengalami kekurangan stok dari yang dibutuhkan (yakni sekitar 2.975 tablet per bulan berdasarkan data dalam LPLPO bulan Mei 2017). Hal ini disebabkan karena tablet besi yang seharusnya didapatkan langsung dari Gudang Farmasi Kesehatan (GFK), tidak kunjung ada.

Adanya defisit jumlah tablet besi yang dialami tersebut, membuat Puskesmas Kalijudan melakukan peminjaman tablet besi kepada puskesmas yang memiliki stok lebih banyak. Hal tersebut dilakukan untuk dapat menutupi kekurangan dan disamping menunggu alokasi dari GFK telah ada. Berdasarkan hasil observasi per bulan Juli 2017, didapatkan bahwa stok dari tablet besi yang ada di gudang farmasi puskesmas berjumlah 200 tablet. Ketersediaan tablet besi itu sendiri menurut hasil penelitian di Puskesmas Bara-Baraya Provinsi Sulawesi Selatan dan di Kecamatan Sokaraja Kabupaten Banyumas menunjukkan adanya pengaruh yang diberikan atau hubungan antara kepatuhan ibu hamil mengkonsumsi tablet besi dengan ketersediaan tablet besi di puskesmas $^{15,16}$. Tetapi faktor ketersediaan tablet besi yang memiliki pengaruh pada kepatuhan bumil mengkonsumsi tablet tersebut, belum tentu bisa menggambarkan kepatuhan bumil di Kota Surabaya.

Sementara itu, alat yang digunakan untuk memeriksa hemoglobin $(\mathrm{Hb})$ ibu hamil adalah hematology analyzer yang dilakukan oleh petugas laboratorium. Dalam penggunaan alat periksa ini, sel darah yang telah pecah atau akan pecah bisa mempengaruhi hasil pemeriksaan yang dilakukan ${ }^{17}$. Pemeriksaan $\mathrm{Hb}$ dengan menggunakan alat hematology analyzer akan dilakukan pada ibu hamil pada saat kunjungan pertamanya ke puskesmas. Hematology analyzer dapat memberikan analisis yang akurat terhadap jumlah sel darah merah, membedakan 5 macam sel darah putih, dan mampu mengidentifikasi neutrofil, limfosit, basofil, monosit, serta eosinofil ${ }^{18}$. Hal ini didukung pula dengan pernyataan informan yang menyebutkan bahwa penggunaan hematology analyzer dikarenakan memiliki kelebihan mampu memeriksa dan menganalisis nilai dari komponen darah lebih dari satu jenis (bukan hemoglobin saja).

Segi aspek proses, perencanaan kebutuhan tablet besi di tingkat puskesmas dilakukan oleh petugas farmasi/apotek dan mulai disusun sejak akhir tahun sebelumnya 
bersamaan dengan jenis suplemen atau obatobatan lainnya. Pada hasil penelitian yang dilakukan di Puskesmas Madakareya Kota Makassar tahun 2013 juga didapatkan bahwa petugas yang melakukan perencanaan kebutuhan tablet besi ialah petugas farmasi puskesmas $^{14}$. Perhitungan kebutuhan tablet besi menggunakan rumus jumlah kebutuhan tiap bulan dikalikan dua belas (jumlah bulan dalam satu tahun) dan ditambahkan dengan nilai buffer stock (kebutuhan 3 bulan). Perencanaan tersebut dilakukan sebanyak satu kali yang tertulis dalam dokumen online dan Laporan Pemakaian dan Lembar Permintaan Obat (LPLPO) milik puskesmas. Akan tetapi khusus untuk tahun 2017, Puskesmas Kalijudan diarahkan oleh DKK untuk tidak memasukkan tablet besi ke dalam daftar permintaan obat, karena Puskesmas Kalijudan akan mendapatkan langsung tablet besi dari Gudang Farmasi Kesehatan (GFK) Dinas Kesehatan Kota Surabaya.

Pendistribusian tablet besi ialah kegiatan dari alur tablet besi dikirimkan, yang berasal pusat menuju ke tempat fasilitas pelayanan kesehatan yang dapat menjangkau sasaran ${ }^{19}$. Pendistribusian tablet besi yang dilakukan oleh puskesmas adalah wujud kerja sama lintas program antara gizi dan KIA, yang memiliki kesamaan sasaran yakni ibu hamil20. Pendistribusian tablet yang dilakukan oleh tenaga kesehatan saat ini, terfokus di puskesmas induk dan puskesmas pembantu (pustu). Distribusi tablet besi itu sendiri sebenarnya dapat dilakukan melalui beberapa cara atau tempat yakni saat bumil melakukan kunjungan ANC, saat kelas bumil, saat bidan berkunjung door to door, ataupun dapat diperoleh di Posyandu ${ }^{19}$. Jumlah tablet besi yang didistribusikan kepada ibu hamil untuk satu kali kunjungannya maksimal ialah 15 tablet, atau mengikuti jadwal kontrol ibu hamil (seperti contoh 7 tablet atau 14 tablet). Hal ini dilakukan sebagai salah satu upaya menghadapi stok tablet besi yang masih rendah. Tablet besi ibu hamil untuk disisa waktu yang ada dalam satu bulannya, akan diarahkan untuk didapatkan melalui Bidan Praktik Swasta/Mandiri yang berada di lingkungan puskesmas agar bumil tetap bisa mendapatkan minimal 90 tablet selama masa kehamilan.

Monitoring merupakan salah satu bagian yang terdapat dalam sistem manajemen. Monitoring yang dimaksudkan dalam konteks pembahasan ini ialah kegiatan yang ditujukan untuk memantau kepatuhan ibu hamil mengkonsumsi minimal 90 tablet besi selama masa kehamilan. Tenaga kesehatan yang terlibat dalam kegiatan monitoring ialah bidan puskesmas (mayoritas oleh bidan kelurahan). Cara yang digunakan dalam melakukan monitoring ialah dengan wawancara sederhana, meliputi apakah obat telah habis dikonsumsi atau belum. Penggunaan wawancara secara sederhana oleh bidan saat melakukan monitoring juga terdapat dalam hasil penelitian yang dilakukan oleh di Puksesmas Madakareya Kota Makassar ${ }^{14}$.

Wawancara tersebut biasanya ditujukan kepada ibu hamil secara langsung. Selain ibu hamil, wawancara tersebut juga bisa dilakukan atau ditujukan kepada pendamping ibu hamil yang datang bersamanya (seperi suami maupun anggota keluarga lainnya). Adapula cara lain yang semestinya dapat digunakan untuk memonitoring kepatuhan yaitu dengan cara membawa sisa keemasan tablet besi sebagai bukti, saat ibu hamil melakukan kunjungan ${ }^{19}$. Selain dengan wawancara, bidan puskesmas juga biasanya melakukan pencocokan dengan data kunjungan ibu hamil untuk bisa mengestimasi apakah obat memang sudah seharusnya habis atau belum.

Kegiatan monitoring yang dilakukan selama ini di Puskesmas Kalijudan, ternyata belum disertai dengan adanya pelaporan khusus hasil monitoring. Dalam penelitian di Puskesmas Madakareya Kota Makassar pun disebutkan tidak disertainya pelaporan khusus untuk hasil pelaksanaan monitoring kepatuhan ibu hamil mengkonsumsi tablet besi ${ }^{14}$. Pedoman yang dibuat oleh Kementerian Kesehatan RI dan Millennium Challenge Account-Indonesia melampirkan lembar khusus untuk monitoring konsumsi ibu hamil terhadap tablet besi yang seharusnya dapat digunakan dalam kegiatan monitoring kepatuhan ibu hamil ${ }^{19}$. Sampai saat ini, laporan 
yang secara rutin setiap bulannya ialah jumlah ibu hamil yang mendapatkan tablet besi.

Pengorganisasian tenaga kesehatan merupakan salah satu elemen penting dalam fungsi manajemen. Pengorganisasian didefiniskan sebagai upaya dalam pemanfaatan seluruh sumber daya yang dimiliki dan dikumpulkan agar mampu mencapai tujuan dari organisasi, secara efisien $^{21}$. Pengorganisasian dan struktur organisasi tenaga kesehatan khusus untuk program suplementasi tablet besi di Puskesmas Kalijudan hingga kini belum ada. Hal ini disebabkan karena program suplementasi tablet besi, mempunyai keterkaitan pula dengan program antenatal care (ANC) dan juga bukan program baru (telah berjalan). Penanggung jawab dari program suplementasi tablet besi pada bumil di Puskesmas Kalijudan adalah petugas gizi dan bidan. Pelaporan hasil dari program (cakupan pemberian tablet besi), menjadi milik petugas gizi namun data berasal dari hasil pencatatan yang dilakukan oleh bidan. Adapun yang bertanggung jawab dalam memberikan/menyampaikan KIE mengenai tablet besi dan anemia kepada ibu hamil ialah bidan (bidan koordinator dan bidan kelurahan). Pelaksanaan program tablet besi di Puskesmas Binamu Kabupaten Jeneponto juga memberikan tugas kepada bidan untuk memberikan edukasi tablet besi pada kelompok sasaran ${ }^{13}$.

Segi aspek output, persentase cakupan ibu hamil yang mendapat tablet besi dihitung satu tahun sekali pada setiap akhir tahun sebagai acuan sejauh mana program berjalan. Angka persentase cakupan tersebut, awalnya berasal laporan bulanan jumlah ibu hamil yang mendapatkan tablet besi. Pencatatan laporan bulanan terhimpun di dalam buku kohort ibu hamil yang dimiliki oleh puskesmas. Selain itu, ibu hamil juga akan mendapatkan catatan mengenai pemberian tablet besi yang tercantum dalam buku kontrol miliknya (buku $\mathrm{KIA}$ ). Data jumlah ibu hamil yang menerima tablet besi, tidak hanya terkumpul yang dilakukan di area puskesmas atau unit di bawahnya namun juga berasal dari data kegiatan Pemantauan Wilayah Setempat (PWS). Kegiatan tersebut dilakukan sebagai upaya untuk mendeteksi berapa banyak ibu hamil yang mendapatkan tablet besi di tempat fasilitas pelayanan kesehatan di sekitar wilayah puskesmas. Menurut data laporan bulan Mei 2017 (khusus bumil di wilayah kerja puskesmas), didapatkan bahwa sebanyak 34 bumil telah mendapatkan 30 tablet besi ( $\mathrm{Fe}-1)$ dan 39 tablet besi (Fe-3) telah mendapatkan 90 tablet besi.

Perekapan data jumlah ibu hamil yang mendapatkan tablet besi dilakukan oleh petugas gizi dan bidan koordinator. Perbedaan stuktur laporan yang dimiliki oleh petugas gizi dan bidan terletak pada penulisan jumlah ibu hamilnya. Pada laporan petugas gizi, pencatatan jumlah ibu hamil akan mengikuti pembagian per wilayah kerja puskesmas ataupun terdapat kolom sendiri untuk ibu hamil yang berasal dari luar wilayah kerja puskesmas. Sementara itu, pada laporan yang dimiliki oleh bidan didasarkan pada di mana ibu hamil mendapatkan tablet besi (per tempat pelayanan kesehatan seperti puskesmas induk, pustu, BPM/BPS, dan sebagainya). Dengan kata lain, laporan yang dituliskan oleh bidan lebih secara global dan bukan saja direkap khusus untuk ibu hamil dari wilayah kerja puskesmas.

Beradasarkan data yang didapatkan dari Dinas Kesehatan Kota Surabaya mengenai persentase cakupan pemberian tablet besi kepada ibu hamil tahun 2014-2017, menunjukkan adanya tren yang meningkat. Akan tetapi adanya tren peningkatan ini, belum tentu diikuti dengan pelaksanaan program di lapangan yang telah sesuai dengan arahan pihak terkait. Peningkatan cakupan pemberian tablet besi, bisa disebabkan karena tenaga kesehatan telah tertib dalam melakukan pencatatan pemberian tablet besi pada ibu hamil. Adapun penelitian sebelumnya yang menyebutkan bahwa peningkatan cakupan tablet besi di Puskesmas Madakareya Kota Makassar, masih diikuti dengan beberapa aspek/tahapan yang masih belum sesuai dengan standar pelaksanaan yang ada namun tidak dijelaskan standar apa yang dimaksud ${ }^{14}$.

Segi aspek outcome, persentase prevalensi anemia tidak bisa diketahui dikarenakan pencatatan yang dilakukan oleh bidan ialah angka kejadian bumil anemia. 
Pencatatan tersebut dilakukan berdasarkan hasil pemeriksaan darah lengkap yang dilakukan oleh bumil saat pertama kali berkunjung ke puskesmas atau K1 yang dilaporkan secara rutin satu bulan sekali kepada pihak DKK. Pencatatan anemia bumil yang dilakukan pada lembar LB3 KIA, dengan rincian baris laporan yakni jumlah bumil dengan $\mathrm{Hb}$ 8-11 $\mathrm{mg} / \mathrm{dL}$ dan $\mathrm{Hb}<8 \mathrm{mg} / \mathrm{dL}$. Menurut data laporan LB KIA bulan Juni 2017 jumlah bumil dengan $\mathrm{Hb} 8-11 \mathrm{mg} / \mathrm{dL}$ dan $<8$ $\mathrm{mg} / \mathrm{dL}$ berjumlah 0 orang bumil.

\section{KESIMPULAN}

Segi aspek input, rentang usia bumil yang banyak ditemui berada pada kelompok 25-27 tahun. Mayoritas usia kandungan bumil yang ditemui ialah 20-23 minggu. Bumil dengan pendidikan terakhir SLTA/Sederajat serta profesi bumil sebagai ibu rumah tangga ialah yang paling banyak ditemui. Adapun bumil yang menjawab dengan benar mengenai definisi anemia, manfaat konsumsi tablet besi, dan efek samping konsumsi tablet masingmasing mencapai $66,6 \%, 73,3 \%$, dan 53,3\%. Tugas/tanggung jawab dari tenaga kesehatan yang terlibat dalam program ialah kolaborasi antara petugas gizi dan farmasi dalam pengadaan/perencanaan tablet besi untuk memenuhi kebutuhan puskesmas dan bidan yang bertugas dalam pemberian talet besi pada ibu hamil. Sementara itu, dana yang digunakan dalam pemenuhan kebutuhan tablet besi berasal dari dana Jaminan Kesehatan Nasional (berdasarkan besaran kapitasi per puskesmas). Ketersediaan tablet besi belum mampu mencukupi kebutuhan pada bulan berjalan. Adapun alat yang digunakan untuk memeriksa hemoglobin pada ibu hamil adalah hematology analyzer dan dioperasikan oleh petugas laboratorium.

Segi aspek proses, perencanaan kebutuhan tablet besi dilakukan setahun sekali namun khusus untuk tahun 2017 angka perencanaan tidak dimasukkan ke dalam daftar permintaan obat farmasi puskesmas. Pendistribusian tablet besi pada ibu hamil, saat ini terfokus pada puskesmas induk dan pustu.
Jumlah tablet yang didistribusi maksimal dalam satu kali kunjungan bumil adalah 15 dan diusahakan hingga mencapai minimal 90 tablet selama masa kehamilan. Monitoring kepatuhan bumil mengkonsumsi tablet besi dilakukan dengan wawancara sederhana yang ditujukan kepada bumil langsung/pendampingnya. Pencatatan maupun pelaporan terhadap hasil kegiatan monitoring kepatuhan minum tablet besi belum ada. Pengorganisasian tanggung jawab/tugas dan struktur pengoganisasian khusus untuk tenaga kesehatan yang terlibat dalam program juga belum ada.

Segi output, angka persentase cakupan program baru akan dihitung apabila tahun akan berganti (dihitung setiap akhir tahun). Pencatatan dan pelaporan yang dilakukan berkaitan dengan tablet besi pada tiap bulannya ialah jumlah ibu hamil yang mendapatkan tablet besi. Pencatatan tersebut bisa ditemui pada laporan yang dimiliki oleh petugas gizi dan bidan. Jumlah bumil yang ada di wilayah kerja puskesmas mendapat 30 tablet sebanyak 30 orang dan yang mendapat 90 tablet sebanyak 39 orang (data bulan Mei 2017). Adapun peningkatan cakupan dalam tiga tahun terakhir disebabkan karena pencatatan yang dilakukan oleh tenaga kesehatan telah tertib dan teratur.

Segi outcome, angka prevalensi anemia pada ibu hamil belum bisa diketahui. Hal ini dikarenakan pencatatan yang dilakukan oleh tenaga kesehatan ialah dalam bentuk jumlah kasus ibu hamil anemia. Data jumlah kasus tersebut juga yang kemudian dilaporkan setiap bulannya oleh tenaga kesehatan terkait kepada DKK. Menurut data laporan bulanan (data bulan Juni 2017) bahwa jumlah bumil $\mathrm{Hb}$ 8-11 $\mathrm{mg} / \mathrm{dL}$ atau $\mathrm{Hb}<8 \mathrm{mg} / \mathrm{dL}$ berjumlah 0 orang. Secara keseluruhan, pelaksanaan program tablet besi di Puskesmas Kalijudan belum dapat dikatakan berjalan dengan baik. $\mathrm{Hal}$ itu dikarenakan masih terdapat beberapa kendala yang ditemui seperti ketersediaan tablet besi yang masih rendah, belum adanya pencatatan mengenai hasil monitoring kepatuhan minum tablet besi, dan belum cukupnya jumlah tablet besi yang seharusnya diterima bumil. 


\section{ACKNOWLEDGEMENT}

Terima kasih penulis berikan kepada: Badan Kesatuan Bangsa dan Politik Kota Surabaya, Dinas Kesehatan Kota Surabaya, dan Puskesmas Kalijudan yang telah memberikan izin untuk pelaksanaan penelitian ini. Seluruh dosen serta staf dari Departemen Gizi Kesehatan dan Program Studi IImu Gizi Fakultas Kesehatan Universitas Airlangga terutama kepada dosen pembimbing atas bimbingan dan pengarahan yang selama ini telah diberikan kepada penulis.

\section{REFERENSI}

1. Fikawati, S., Syafiq, A., \& Karima, K. Gizi Ibu dan Bayi. Jakarta: PT. RajaGrafindo Persada, 2015. p: 11.

2. Kementerian Perencanaan Pembangunan Nasional/Badan Perencanaan Pembangunan Nasional (BAPPENAS). Rencana Aksi Nasional Pangan dan Gizi 2011-2015, 2011. Available from http://www.bappenas.go.id/ files/4613/5228/2360/ran-pg-20112015.pdf Diakses pada tanggal 17 Januari 2017.

3. Sharman, J., B.,\& Shankar, M. An Overview of Anemia in Preganancy. JIMSA, 2010; 23(4). Available from http://medind.nic.in/jav/t10/i4/javt10 i4p253.pdf Diakses pada tanggal 17 Januari 2017.

4. World Health Organization (WHO). Daily Iron and Folic Acid Supplementation in Pregnant Women, 2012. Available from http://apps.who.int/iris/bitstream/1066 5/77770/1/9789241501996eng.pdf?ua= 1 Diakses pada tanggal 14 Maret 2014.

5. Badan Penelitian dan Pengembangan Kesehatan Kementerian Kesehatan RI. Riset Kesehatan Dasar Tahun 2013, 2013; 1-348. Available from http://www.depkes.go.id/resources/do wnload/general/Hasil\%20Riskesdas\%202 013.pdf Diakses pada tanggal 7 Maret 2017.

6. Palihawadana, T., S., Goonewarde, I., M., R., Motha, M., B., C.,\& Williams, H., S., A.
Iron Deficiency Anemia in Pregnancy: Diagnosis, Prevention, and Treatment. Sri Lanka Journal of Obstetric and Gynaecology, 2014; 36(3). Available from

https://www.ncbi.nlm.nih.gov/pubmed/ 22138002 Diakses pada 1 Februari 2017.

7. Faris, N. Prevalence of Iron Deficiency Anemia Etiological and Prevention. European Journal of Biological and Medical Science Research, 2014; 2(2). Available from http://www.eajournals.org/wp-

content/uploads/ Prevalence-of-Irondeficiency-Anemia.pdf Diakses pada 10 Februari 2017.

8. Charles, C., V., Summerlee, A., JS.,\& Dewey, C. Anemia in Cambodia: Prevalence, Etiology, and Research Needs. Asia Pasific Journal of Clinical Nutrition, 2012; 21(2). Available from http://apjcn.nhri.org.tw/server/APJCN/2 1/2/171.pdf Diakses pada 23 Feburari 2017.

9. Direktorat Gizi Masyarakat. Program Penanggulangan Anemia Gizi Pada Wanita Usia Subur (WUS) (Safe Mother Project: A Partnership and Family Approach Kesehatan Ibu: Kemitraan dan Pendekatan Keluarga). Jakarta: Direktorat Jendral Bina Gizi Masyarakat Departemen Kesehatan, 2008. p: 1-9.

10. Amirin. T. Pokok-Pokok Teori Sistem. Jakarta: PT. RajaGrafindo Persada, 2003. p: 6-7.

11. Mulyana, D. Metodologi Penelitian Kualitatif. Bandung: PT. Remaja Rosdakarya, 2004. p: 145-146.

12. Kementerian Kesehatan RI. Peraturan Menteri Kesehatan (Permenkes) RI Nomor 75 Tahun 2014 Tentang Puskesmas, 2014; p: 10. Available from http://www.aidsindonesia.or.id/uploads /20141210110659.PMK_No_75_Th_201 4_ttg_Puskesmas.pdf Diakses pada tanggal 17 September 2017.

13. Dahlia, S., Sirajuddin, S., \& Citrakeusumasari. Evaluasi Program Pemberian Tablet Besi Ibu Hamil di Wilayah Puskesmas Binamu Kecamatan Binamu Kabupaten Jeneponto. E-Journal 
Program Pascasarjana Universitas Hasanuddin, 2014. Available from http://pasca.unhas.ac.id/ jurnal/files/ d85bd49a48de2af3e4f15020ee7c7b34.p df Diakses tanggal 30 Januari 2017.

14. Hatta, H., Dachlan, A., M.,\& Salam, A. Studi Pelaksanaan Program Suplementasi Tablet Besi (Fe) untuk Ibu Hamil di Puskesmas Madakareya Kota Makassar, 2013. Repository Universitas Hasanuddin. Available from http://repository.unhas.ac.id/bitstream/ handle/123456789/10499/HELIDA\%20H ATTA\%20K21110279.pdf?sequence=1 diakses pada 30 Januari 2017.

15. Kauthsar, N., Suriah, and Jafar, N. Kepatuhan Ibu Hamil dalam Mengkonsumsi Tablet Besi (Fe) di Puskesmas Bara-Baraya Tahun 2013. EJournal Program Pascasarjana Universitas Hasanuddin, 2013. Available from

http://pasca.unhas.ac.id/jurnal/files/ 2838ec295ddbb $8912 d 283$ bac2b79fa48.pdf Diakses pada tanggal 11 September 2017.

16. Rahmawati, D., Mursiyam, \& Sejati, W. Faktor-Faktor yang Mempengaruhi Kepatuhan Ibu Hamil dalam Mengkonsumsi Tablet Besi di Daerah Sokaraja Tengah, Kecamatan Sokaraja Kabupaten Banyumas. Jurnal Keperawatan Soedirman (The Soedirman Journal of Nursing), 2008; 3(3). Available from http://jks.fikes.unsoed.ac.id/index.php/j ks/article/view/198/92 Diakses pada 11 September 2017.

17. Dewi, D., C., \& Durachim, A. Analysis of Blood Sample Lysis Rate on Hemoglobin Examination Results Using Rayto RT. 7600 Auto Hematology Analyzer. Folica Mediana Indonesia, 014; 50 (4). Available from http://journal.unair.ac.id/downloadfullpapers-fmi25cfac0 36afull.pdf Diakses pada 14 September 2017.

18. Sullivan, E. Hematology Analyzer: From Workhorse to Thoroughbred. LAB MEDICINE, 2006; 37 (5). Available from https://oup.silverchair-
cdn.com/oup/backfile/Content_public/J ournal/labmed/37/5/10.1309_TMQ6T4C BCG408141/3/labmed37-

0273.pdf?Expires $=1509343140 \&$ Signatur e=Ovo9xVBcjtHjn1Y8Lyu2Vw2ZPd6BMjJz PSyallS PUuq7bBSGDlyh1sbCdDfRJUrn4 U4xdixc9mOv7hAa8C-Tsw-

TaOuv8EO2nOjV41tozC4fu7D7Y6R80Se1 HOx0j5YZABWWZgjcVN68aQvLfcwZOydT xiWUEdLSRCMgAx-

IDjItDBT5zDGEehqNqKnNQqeuaxPliChvV VVXU-

q DmNymvTy5bVQaHKcwDzx03blcToA xLhPidHzENaUHq9BZam3T1aBTUgWSw OWzy5WLnWy5MG7DziHMSCltkQES3G G90R8yL-

saAmKa3sS18gfpjn Jh ONiDzPQXu Xz3r g_\&Key-Pair-

Id=APKAIUCZBIA4LVPAVW3Q Diakses pada 29 Oktober 2017.

19. Kementerian Kesehatan RI \& Millennium Challenge Account-Indonesia. Pedoman Program Pemberian dan Pemantauan Mutu Tablet Tambah Darah untuk Ibu Hamil di Wilayah Program Kesehatan dan Gizi Berbasis Masyarakat, 2015. Available from https://www.academia.edu/28222067/P edoman_Program_Pemberian_dan_Pem antauan_Mutu_Tablet_Tambah_Darah_ Untuk_Ibu_Hamil_Millennium_Challeng e_Account_-Indonesia Diakses pada tanggal 27 Januari 2017.

20. Irawati, E. Gambaran Keterpaduan Program KIA dan Gizi dalam Pelaksanaan Distribusi Tablet Fe Ibu Hamil di Puskesmas Perawatan Pangatan Kabupaten Tanah Bumbung Propinsi Kalimantan Selatan Tahun 2012. Skripsi. Depok: Universitas Indonesia, 2012; p. 66. Available from http://lib.ui.ac.id/file?file=digital/20319 818-S-PDF-Elly\%20Irawati.pdf Diakses pada tanggal 11 September 2017.

21. Ekarini, S.,M., B. Organisasi dan Manajemen Pelayanan Kesehatan Dalam Kebidanan. Yogyakarta: Theme Publishing, 2016. p: 9. 